\title{
SEJARAH SOSIAL HUKUMAN PEMINUM KHAMR
}

\author{
Arif Jamaluddin Malik \\ Institut Agama Islam Negeri Sunan Ampel, Jl. A Yani I 17 Surabaya | \\ Arjamal77@gmail.com
}

\begin{abstract}
Penalty for a drinker can not be separated from the development and changes in society. As one of the many provisions of a criminal penalty, drinker should remain be punished. However, in practice, there are differences in accordance with the implementation of penalty for a drinker. It is about the amount and limit of the punishment given to a drinker. This is because al-Qur'an does not explicitely mention the legal sanctions for a drinker. In contrast to the punitive sanction for the variant of violations of a criminal penalty, such as fornication, adultery, and theft of the mentioned amount and limit of their sentence. The differences in the application of a criminal penalty for drinkers at the Prophet's time time and after indicate that although the substantive criminal penalty should remain in force, but in the application might be heavier or at least equal as the former penalty. Those facts indicate that Islamic law is related to the changes and development of society. Thus, there is an interplay circumstance between Islamic law and the developments and changes in society, or in otherwise.
\end{abstract}

Keywords: History, penalty, liquor, criminal penalty.

Abstrak: Sanksi hukuman bagi peminum khamr tidak dapat dilepaskan dari keterkaitannya dengan perkembangan dan perubahan masyarakat. Sebagai salah satu dari sekian banyak ketentuan yang bersifat hudud, peminum khamr harus tetap dihukum. Akan tetapi, dalam praktek pelaksanaan hukuman bagi peminum khamr ini terdapat perbedaan tentang jumlah dan batas hukuman yang diberikan kepada peminum khamr. Hal ini dikarenakan al-Qur'an tidak menyebut sanksi hukum bagi peminum khamr. Berbeda dengan sanksi hukuman bagi pelanggaran terhadap varian hudud lainnya seperti perzinaan, tuduhan perzinahan, dan pencurian yang disebutkan jumlah dan batasan hukumannya. Perbedaan penerapan sanksi hukuman bagi peminum khamr pada masa Rasul saw dan masa sesudahnya mengindikasikan bahwa meskipun secara substantif sanksi hukuman itu harus tetap 
diberlakukan, tetapi dari segi penerapannya dapat menjadi lebih berat atau paling tidak, sama, dengan sanksi hukuman sebelumnya. Dari indikasi itu dapat ditemukan kenyataan bahwa hukum Islam terkait dengan perubahan dan perkembangan masyarakat. Dengan demikian, maka terjadi situasi dan kondisi yang saling mempengaruhi antara hukum Islam dengan perkembangan dan perubahan masyarakat, maupun sebaliknya.

Kata Kunci: Sejarah, hukuman, khamr, hudud.

\section{Pendahuluan}

Hukum Islam yang bersumber dari al-Qur'an dan Sunnah mempunyai tujuan untuk mendidik pribadi yang baik, menjadikan keadilan di masyarakat dan mewujudkan kemaslahatan bagi umat manusia.

Terealisirnya kemaslahatan umat manusia bertumpu kepada terpeliharanya lima unsur pokok kehidupan yaitu: agama, jiwa, akal, harga diri (keturunan), dan harta benda. ${ }^{1}$ Kehidupan manusia tidak akan sejahtera tanpa terpeliharanya lima unsur pokok tersebut.

Akal sebagai salah satu unsur pokok perlu dipelihara agar seseorang tidak menjadi beban masyarakat, tidak menjadi sumber kejahatan, atau penyakit bagi masyarakat. Untuk mencegah hal tersebut, diperlukan kesadaran individu untuk mempertimbangkan baik-buruk dan manfaat-madharat dari perbuatannya. $^{2}$

Berkaitan dengan masalah pemeliharaan akal di atas, makalah ini membahas tentang khamr, khususnya yang berkaitan dengan sejarah sosial diberlakukannya hukuman bagi peminum khamr. Fokus kajian masalah ini adalah untuk melihat seberapa besar pengaruh hukum Islam terhadap masyarakat dan perubahannya, atau mungkin sebaliknya.

\footnotetext{
I 'Abd al-Wahhab Khallaf, 'IIm Usul al-Fiqh, (Kuwayt: Dar al-Qalam, 1978), 200.

2 Muhammad Abu Zahrah, Usul al-Figh, (Beirut: Dar al-Fikr al-'Arabiy, t.t.), 366-368.
}

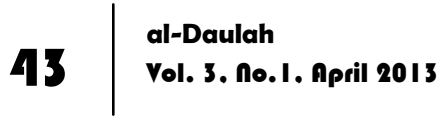




\section{Pengertian Khamr}

Khamr yang berasal dari kata (خامر) berarti mendekati dan mencampuri. ${ }^{3}$ Khamr juga dapat berarti menutupi, sehingga khamr diartikan sebagai jenis minuman yang memabukkan dan menutupi kesehatan akal. ${ }^{4}$

Menurut Abu Hanifah, yang dimaksud khamr adalah minuman dari perasan anggur yang dimasak sampai mendidih serta mengeluarkan buih. Sari dari buih inilah yang mengandung unsur memabukkan. Sedangkan menurut al-Shafi'i juga Jumhur Ulama selain Abu Hhanifah, khamr adalah seluruh minuman yang mengandung unsur yang memabukkan bukan hanya yang terbuat dari perasan anggur. ${ }^{5}$

Pendapat kedua yang dikemukakan oleh al-Shafi'i merujuk kepada pemahaman sahabat Nabi saw terhadap diharamkannya khamr sebagai minuman yang memabukkan. Pemahaman ini bersumber pada penjelasan Nabi saw bahwa setiap yang memabukkan adalah khamr dan setiap khamr adalah haram. ${ }^{6} \mathrm{Di}$ samping itu, juga didasarkan kepada penjelasan Nabi saw bahwa dari anggur juga bisa dibuat khamr, demikian pula dengan kurma, madu, dan gandum. Penjelasan terakhir ini diriwayatkan oleh Abu Dawud dari Ibn ‘Umar.

\section{Sejarah Pelarangan Khamr}

Di dalam al-Qur'an terdapat empat ayat yang berkaitan dengan masalah khamr dan pelarangannya.7 Satu ayat (pertama) diturunkan di Makkah dan tiga ayat lainnya diturunkan di Madinah. Ayat-ayat tersebut secara kronologis sebagai berikut:

\footnotetext{
${ }^{3}$ Ibn Mandhur, Lisan al-Lisan Tahdhib Lisan al-'Arab, (Beirut: Dar al-Fikr, 1993), 336.

${ }^{4}$ Abdul Aziz Dahlan, et. al., Ensiklopedi Hukum Islam, (Jakarta: Ikhtiar baru Van Hoeven, 1997), 1180 .

${ }^{5}$ Ibid., I810-181 I. Lihat juga al-Maraghi, Tafsir al-Maraghiy,(Beireut: Dar al-Fikr, t.t.), I39., dan Muhammad 'Ali al-Sabuni, Rawai' al-Bayan Tafsir Ayat al-Ahkam min al-Qur'an, (Beirut: Dar alFikr, t.t.), 566.

${ }^{6}$ al-Maraghi Tafsir al-Marâghiy, 134.

7 al-Sabuni, Rawâi', 272.
} 
1. Ayat 67 Surat al-Nahl:

"Dan dari buah kurma dan anggur kamu buat minuman yang memabukkan dan rizki yang baik. Sesungguhnya pada yang demikian itu benar-benar terdapat tanda (kebesaran Allah) bagi orang yang memikirkan." 8

2. Ayat 219 Surat al-Baqarah:

"Mereka bertanya kepadamu tentang khamr dan perjudian, katakanlah pada keduanmya terdapat dosa besar dan beberapa manfaat bagi manusia tetapi dosa keduanya lebih besar dari manfatnya." 9

3. Ayat 43 Surat al-Nisa':

"Hai orang-oreang yang beriman janganlah kamu shalat sedang kamu dalam keadaan mabuk, sehingga kamu mengerti apa yang kamu ucapkan (jangan pula hampiri masjid) sedang kamu dalam keadaan junub, kecuali sekedar berlalu saja...."10

4. Ayat 90 Surat al-Maidah :

"Hai orang-orang yang beriman sesungguhnya (meminum) khamr, berjudi, (berkorban untuk) berhala, mengundi nasib dengan anak panah, adalah perbuatan kotor termasuk perbuatan setan, maka jauhilah perbuatan itu agar kamu mendapatkan keberuntungan."11

Ayat 67 Surat al-Nahl turun bersamaan dengan ayat-ayat yang menjelaskan tanda-tanda keesaan Allah dan kekuasaan-Nya untuk menurunkan hujan sehingga muncul tumbuh-tumbuhan walaupun di tanah gersang, mengeluarkan air susu dari binatang ternak, menjadikan buah-buahan sebagai manisan dan minuman (termasuk khamr), dan produksi madu dari lebah yang berguna untuk kesehatan dan pengobatan. ${ }^{12}$

Pada saat turun ayat tersebut, masyarakat Arab (termasuk para sahabat) masih menkonsumsi minuman keras yang bahan-

\footnotetext{
${ }^{8}$ Mujamma' Khadim al-haramayn, al-Qur'an dan Terjemahnya, (Madinah: t.p., t.t.), 4I2.

${ }^{9}$ Ibid., 53.

${ }^{10}$ bid., 125.

"Ibid., 176.

${ }^{12}$ al-Maraghi, Tafsir, vol. 5, 102.
} 
bahannya terbuat dari buah-buahan. Di samping itu, juga sebagai komoditi perdagangan. Meskipun pada tahap ini al-Qur'an telah menyebutkan adanya unsur yang memabukkan dalam kurma dan anggur, di samping juga sebagai rizki yang baik, tetapi umat Islam tetap mengkonsumsinya oleh karena mereka merasa bahwa, minuman keras masih halal bagi mereka. ${ }^{13}$ Dengan kata lain, pada tahapan ini secara tidak langsung umat Islam dituntut untuk mulai menjauhi khamr.

Sedangkan ayat 219 Surat al-Baqarah turun berkenaan dengan 'Umar bin Khattab, Mua'dh bin Jabal, dan segolongan kaum Ansar yang meminta penjelasan kepada Rasul saw tentang khamr dan perjudian yang keduanya dapat menimbulkan efek negatif berupa hilangnya kesadaran dan harta benda. Sebagai jawabannya Allah SWT menurunkan ayat tersebut. ${ }^{14}$ Pada tahap ini, umat Islam secara langsung dituntut untuk menjauhi khamr tetapi dengan cara memperbandingkan dua sisi; sisi manfaat (positif) dan sisi madharat (negatif).

Dengan turunnya ayat 219 Surat al-Baqarah, segolongan sahabat tidak mau mengkonsumsi khamr lagi karena minum khamr berdosa besar sesuai (dengan bunyi ayat قل فيهما اثم كبير ). Sedangkan segolongan lainnya masih mengkonsumsi khamr oleh karena melihat masih adanya manfaat (ومنافع للناس), meskipun dosanya lebih besar (واثمهما اكبر من نفعهما). Keadaan ini terus berlangsung sampai terjadinya peristiwa salah baca terhadap ayat dua dan tiga surat al-Kafirun (اعبد ما تعبدون) menjadi pada waktu jamaah shalat Maghrib. ${ }^{15}$ Sebelum shalat, 'Abd al-Rahman bin 'Awf mengundang para sahabat Nabi dalam jamuan makan dan minum khamr. Selesai jamuan itu, mereka melaksanakan shalat Maghrib berjamaah. Dari kesalahan yang cukup fatal itu, maka turunlah ayat 43 Surat al-Nisa'.16 Kesalahan itu terjadi akibat

\footnotetext{
13 al-Sabuni, Rawâi', 272.

14 al-Wahidi, Asbab al-Nuzul, (Beirut: Dar al-Fikr, 1987), 102.

${ }^{15}$ Sahabat yang diminta maju untuk menjadi imam shalat ini adalah 'Ali bin Abi Thalib. Lihat alTabari, Tafsir al-Tabariy, (Beirut: Dar al-Fikr, t.t.) 376.

${ }^{16}$ al-Wahidi, Asbab, 184.
} 
ketidaksadaran akal yang telah dipengaruhi oleh zat kimia khamr yang merasuk ke saraf otak. Pada tahap ini, khamr sudah diharamkan ketika mendekati waktu shalat. Ini berarti bahwa (secara logika) para sahabat masih boleh mengkonsumsi khamr jika telah selesai shalat atau jika masih jauh dengan waktu shalat. Hukum haram pada tahap ini tidak bersifat mutlak, tetapi temporal (al-tahrim al-juz'iy).

Akibat ketidakjelasan status hukum dari khamr itu, di kalangan sahabat masih terbiasa jamuan makan yang disertai minuman khamr. Menurut penuturan Sa'ad bin Abi Waqqas yang diriwayatkan Muslim, dia pernah diajak oleh segolongan orangorang Muhajirin untuk jamuan makan dan minum khamr di suatu perkebunan. Pada saat pesta jamuan itu, Sa'ad menemukan daging panggang yang diolesi khamr. Ia ikut makan dan minum khamr bersama mereka. Akibat makan daging panggang yang diolesi khamr tersebut - juga minum khamr-Sa'ad berbicara tanpa kontrol (ngomel) memanggil golongan Ansar dan Muhajirin. Di hadapan mereka Ia berkata, "Golongan Muhajirin lebih baik daripada Golongan Ansar". Mendengar perkataan ini, seorang laki-laki Ansar menghampirinya dengan memukul kepalanya sehingga berdarah hidungnya. Setelah peristiwa ini Sa'ad melaporkan kepada Rasul saw. Sebagai jawabannya, Rasul saw mendapatkan wahyu ayat 90 Surat al-Maidah. ${ }^{17}$

Menurut riwayat Ahmad bin Hanbal yang bersumber dari Abu Muyasarah bahwa 'Umar bin Khattab berdoa memohon kepada Allah penjelasan sejelas-jelasnya tentang status khamr. ${ }^{18}$ Maka ketika turun ayat 219 Surat al-Baqarah, segera disampaikan kepada 'Umar. Setelah dibacakan di hadapan 'Umar, 'Umar berdoa kembali seperti semula. Maka ketika turun ayat 43 Surat alNisa', disampaikanlah ayat tersebut kepada 'Umar. Sebagaimana semula Ia berdoa kembali untuk mendapatkan penjelasan yang lebih tegas. Maka setelah itu turunlah ayat 90 Surat al-Maidah.

\footnotetext{
${ }_{17}$ al-Naysaburi, Asbab al-Nuzul, (Beirut: Dar al-Fikr, 1998), 138.

${ }^{18}$ Lafaz doanya adalah اللهم بين لنا فى الخمر بيانا شافيا
} 
Setelah turunnya ayat ini, Ia berkomentar: "Ya Allah kami sudah berhenti (intahayna ya rabbana)" ${ }^{19}$ Dengan diturunkannya ayat 90 tersebut, maka khamr diharamkan secara mutlak (al-tahrim al-kulliy) selama-lamanya.

Dari beberapa tahapan di atas, menunjukkan bahwa salah satu prinsip dasar yang sangat jelas terlihat dari sisi pemberlakuan hukum kaitannya dengan pelarangan minuman keras adalah adanya pentahapan (al-tadarruj). ${ }^{20}$ Dengan pentahapan ini para sahabat dan umat Islam saat itu tidak merasa shock dan siap dalam menerima hukum baru yang terkandung dalam sebuah ayat. Dalam kaitan ini patut pula disimak penuturan 'Aishah r.a. bahwa, mula-mula ayat al-Qur'an yang diturunkan itu terpisah dalam menyebutkan surga dan neraka. Setelah mantap keislaman orangorang, maka turunlah yang membicarakan tentang halal dan haram. Kalau turunnya itu sejak permulaan "Janganlah kalian minum khamr"! pastilah mereka menjawab :"Kami tidak akan mau meninggalkan selamanya" dan seterusnya. ${ }^{21}$ Lebih lanjut Subhi Salih menyebutkan bahwa pentahapan-pentahapan diharamkannya khamr adalah karena setting sosial masyarakat Arab pada saat itu yang tidak bisa lepas dari khamr. Khamr sepertinya sudah mendarah daging dan menjadi bagian dari gaya hidup mereka. Di sinilah Islam membedakan antara al-a'maq (masalah-masalah yang mendalam yang tidak dapat dilarang secara langsung sekaligus) dengan al-sathiyyat (masalah-masalah yang tidak terlalu mendalam atau bersifat permukaan yang pelarangannya dapat dilakukan sekaligus). Islam dalam hal ini memilih sikap sangat hati-hati (pelan tapi pasti), di mana sikap ini menjamin bahwa pelan atau lamban tetapi dengan ketentuan

\footnotetext{
${ }^{19}$ bid., 139.

20 'Abd al-Wahhab Khallaf, Khulasah Tarikh al-Tashri' al-Islamiy, terj. Aziz Masyhuri, (Semarang: Ramadhani, t.t.), 19. Lihat juga dalam 'Abd al-Qadir 'Awdah, al-Tashri' al-Jina'ly al-Islamiy, (t.t. : Muassasah al-Risalah, t.t.), 496.

${ }^{21}$ Subhi al-Salih, Mabahith fi 'Ulum al-Qur'an, (Beirut: Dar al-'Ilm li al-malayin, I988), 56.
} 
hukum yang jelas, lebih baik daripada cepat tetapi hasilnya berantakan.22

\section{Hikmah Diharamkannya Minuman Keras}

Khamr yang merupakan induk dari segala mcam dosa (umm al-kabâ'ir) memiliki madharat yang luar biasa bagi kehidupan manusia. Dari khamr inilah muncul berbagai macam dosa yang dapat membahayakan jiwa, tubuh, akal, dan harta benda (ini dapat disimak dari ayat 91 Surat al-Maidah yang menyebutkan tentang dampak negatif minuman keras dan perjudian).

'Ali al-Sabuni menyebutkan bahwa hikmah diharamkannya meminum khamr adalah:

1. Khamr dapat menghilangkan (merusak) akal manusia sehingga peminumnya menjadi seperti orang gila;

2. Merusak kesehatan manusia. ${ }^{23}$

Tentu masih banyak hikmah-hikmah lainnya, tetapi dua hal yang telah disebut di atas tampaknya cukup merepresentasikan dampak negatif meminum minuman keras. Dari perspektif Ushul Fiqh, dua hal tersebut (akal dan jiwa) termasuk dalam wilayah aldaruriy yang harus dipelihara karena menjadi inti tujuan disyariatkannya pengharaman khamr.

Sebenarnya, dampak negatif mengkosumsi khamr tidak hanya terbatas pada dua hal tersebut, tetapi juga pada agama, keturunan dan harta benda. Dampak negatif pada agama adalah, dengan mengkosumsi khamr, maka orang menjadi tidak patuh pada perintah Allah, misalnya enggan mengerjakan shalat dan lain sebagainya. Termasuk menjadi tidak patuh untuk meninggalkan larangan-larangan Allah, karena dengan mengkosumsi khamr maka kejahatan-kejahatan lanjutan akan dengan mudah dilakukan. Dengan demikian, maka dapat membahayakan keberlangsungan pelaksanaan syariat Islam.

${ }^{22}$ Ibid., 57.

${ }^{23}$ al-Sabuni, Rawâ'i', 273. 
Adapun dampak negatif pada keturunan adalah, dengan mengkosumsi khamr -terlebih jika menjadi pecandu khamr-, maka keturunan yang lahir dari orang tua yang gemar mengkosumsi khamr akan menjadi keturunan yang lemah akalnya, dan tidak menutup kemungkinan juga akan menjadi generasi peminum khamar seperti orang tuanya. Hal ini karena ketika seorang suami melakukan hubungan suami istri dalam keadaan mabuk oleh khamr akan berpengaruh kepada keturunan yang kelak akan dilahirkan. Di samping itu dengan kebiasaan orang tua yang mengkosumsi khamr, juga akan berpengaruh pada perilaku anakanaknya mengingat keteladanan orang tua sangat berperan besar pada pembentukan karakter anak. Anak-anak akan mencoba untuk meniru kebiasaan orang tuanya yang suka mengkosumsi khamr dan mabuk-mabukan.

Sedangkan dampak negatif pada harta benda adalah, dengan mengkosumsi khamr maka keuangan yang dipakai untuk membeli khamr tentu akan menjadi pengeluaran yang tidak mendatangkan manfaat. Terlebih jika sudah menjadi pecandu, maka kebutuhan untuk membeli khamr yang tidak mendatangkan manfaat itu akan dapat mengalahkan kebutuhan prioritas yang harus dipenuhi seperti untuk sandang, pangan dan lain sebagainya. Tidak menutup kemungkinan juga, seorang pecandu khamr akan mencoba untuk beralih menjadi pecandu narkoba karena dari segi pergaulan, pecandu-pecandu barang haram itu biasanya berkaitan satu dengan yang lain. Dengan menjadi pecandu narkoba, maka pengeluaran keuangan juga semakin besar, karena jenis narkoba apapun nilainya bias jadi lebih besar daripada khamr. Jika pengeluaran keuangan sudah sangat besar, sementara penghasilan tidak seimbang, maka akan muncul kajahatan-kejahatan dengan kekerasan, misalnya perampokan, dengan tujuan untuk dapat memenuhi kecanduan khamr maupun narkoba yang dialami.

Secara tidak langsung, pecandu khamr juga dapat menjadi rusak harga dirinya karena dengan memperhatiakn dampak negatif kosumsi khamr akan membuat orang lain memiliki stigma 
negatif tentang pribadi si pecandu sehingga dalam pergaulan dan interaksi sosial akan "dijauhi" oleh orang lain. Secara psikis, pecandu khamr akan tersisih dalam kehidupan social, karena masyarakat khawatir terhadap perilaku si pecandu.

\section{Penentuan Hukuman Peminum Khamr}

Para ulama berbeda pendapat mengenai kadar hukuman bagi peminum khamr. Hal ini karena al-Qur'an tidak menentukan hukuman secara pasti dan jelas. Di samping itu, juga karena eksekusi hukuman peminum khamr di masa Nabi bervariasi, yang tidak lebih dari 40 kali hukuman cambuk. Sementara di saat'Umar berkuasa (atas saran 'Abd al-Rahman bin 'Awf) peminum khamr dihukum cambuk 80 kali. ${ }^{24}$

Akibat perbedaan ini, Malik dan Abu Hanifah berpendapat bahwa hukuman peminum khamr adalah dicambuk 80 kali. Sedangkan al-Shafi'i berpendapat hanya 40 kali hukuman cambuk walaupun menurutnya boleh lebih dari 40 kali, di mana selebihnya merupakan hukuman tambahan ( $\left.t a^{\prime} z i r\right)$ dari seorang penguasa. ${ }^{25}$

Menurut al-San'ani, pendapat al-Shafi'i yang mendasarkan kepada praktek Nabi saw dan Abu Bakar merupakan langkah hatihati sehingga orang yang terbukti memuntahkan khamr karena ketidaktahuannya, tidak dapat dihukum. Berbeda denga Malik, orang yang memuntahkan khamr tetap dihukum. Hal ini didsarkan kepada praktik Nabi yang mengeksekusi al-Walid bin 'Uqbah. ${ }^{26}$

Hanya saja, sejak Islam mengharamkan khamr sampai awal abad ke-20, negara-negara Islam baru merealisasikan hukuman peminum khamr, kalau peminum khamr itu tertangkap basah di tempat umum. Hal ini seperti berlaku di negara Mesir. ${ }^{27}$

Selanjutnya, gerakan-gerakan nyata membendung khamr (dan sejenisnya) bukan hanya dari negara-negara Islam saja, tetapi

\footnotetext{
${ }^{24}$ lbid., 506.

${ }^{25}$ Ibid., 505.

${ }^{26}$ al-San'ani, Subul al-Salâm, vol. IV, (Beirut: Dar al-Fikr, 1993), 51 .

27 'Awdah, al-Tashri', 496.
} 
justru dari negara-negara sekuler seperti Amerika Serikat dan India. ${ }^{28}$

Hukum Islam tidak keliru dalam menetapkan ketentuan bahwa pecandu khamr (dan sejenisnya) layak untuk dihukum dengan hukuman yang cukup keras. Bahkan data konkrit menyebutkan mayoritas penghuni lembaga pemasyarakatan (penjara) didominasi oleh para pemabuk (atau sejenisnya). Di Inggris pada tahun 1924, dari jumlah narapidana sebanyak kurang lebih dua puluh ribu orang yang ada di penjara, tidak kurang dari 60 persennya adalah pecandu khamr. Dan menurut Dokter Sullivan (sorang ahli kriminologi ternama) 60\% dari kasus pelecehan seksual terhadap wanita dan kerusakan moral remaja diakibatkan oleh minuman keras. ${ }^{29}$

Sebagaimana hukuman h\}add pada umumnya, dalam hukuman peminum khamr tidak mengenal maaf, kompromi, dan pengguguran. Hal ini karena hukuman peminum khamr murni hak Allah swt. Sedangkan kalau ta'zir, Ulil amri berhak memberikan pengampunan.

Dalam pelaksanaan eksekusi, tidak boleh dilakukan pada saat yang bersangkutan masih dalam kondisi mabuk karena Ia tidak dapat merasakan hukuman. Kemudian apabila eksekusi telah dilakukan pada saat peminum khamr masih mabuk, ada tiga tindakan alternatif yang dapat dilakukan, yaitu: a) diulang (sebagai keharusan), b) cukup (tidak diulang), c) melihat kondisi peminum khamr. ${ }^{30}$

Sebagai hukuman hadd ringan, dalam pelaksanaannya si terhukum tidak melepas bajunya. Dan jika seseorang melakukan kejahatan ganda,misalnya meminum khamr dengan mencuri, maka hukuman yang didahulukan menurut Abu Hanifah adalah hukuman yang berat. Sedangkan menurut al-Shafi'i dan Ahmad, hadd khamr didahulukan agar kedua hukuman tersebut dapat

\footnotetext{
${ }^{28}$ lbid., 497.

${ }^{29}$ al-Jurjani, Hikam al-Tashri' wa Falsafatuh, (Beirut: Dar al-Fikr, t.t.), 28 I-282.

30 lbid., 507.
} 
dirasakan oleh si terhukum. Sementara Malik menganggap sama untuk mendahulukan yang berat dan ringan. Dalam arti, terserah kepada kehendak penguasa. ${ }^{31}$

Penerapan sanksi hukum kepada peminum khamr, Jika dilihat dari perspektif sosiologis, tampaknya hampir mirip dengan teori tentang perubahan sosial dan hukum yang digagas oleh Durkheim. Menurutnya, dengan meningkatnya diferensiasi dalam masyarakat, reaksi yang kolektif terhadap pelanggaranpelanggaran kaidah-kaidah hukum menjadi berkurang sehingga terjadi pergeseran dari yang bersifat represif menuju yang bersifat restitutif. Artinya, tekanan dialamatkan kepada orang yang menjadi korban atau yang dirugikan, yaitu bahwa segala sesuatunya harus dikembalikan dalam keadaan sebelum kaidahkaidah hukum itu dilanggar. ${ }^{32}$ Apa yang dikemukakan oleh Durkheim tentang hukum represif berguna untuk memahami pentingnya hukuman, termasuk dalam hal ini penerapan sanksi hukum - yang masih debatable - bagi peminum khamr.

Dengan demikian harus dipahami bahwa, penerapan hukuman bagi peminum khamr merupakan upaya untuk mengembalikan dan menegakkan supremasi hukum (apalagi sanksi hukum bagi peminum khamr termasuk kategori hudud yang tidak dapat digugurkan oleh pengampunan manusia) sebagaimana mestinya, sekaligus mendidik dan menimbulkan efek jera bagi pelakunya.

\section{Pengaruh Hukum Islam: Analisis terhadap Hukuman bagi Peminum Khamr}

Dari paparan tentang sejarah pelarangan khamr dan penentuan hukuman bagi peminum khamr, tampak jelas bahwa hokum Islam memiliki pengaruh yang cukup besar dalam mengubah kebiasaan dan perilaku masyarakat yang gemar mengkosumsi khamr. Meskipun dengan berbagai tahapan

31 'Awdah, al-Tashri', II, 507.

32 Soerjono Soekanto, Pokok-pokok Sosiologi Hukum, (Jakarta: PT. Raja Grafindo, 1999), 91-92.

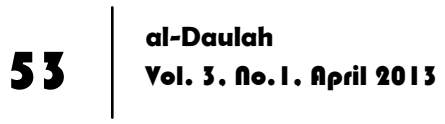


pelarangan, akan tetapi tujuan pelarangan itu telah tercapai. Bahkan, bukan hanya sekedar melarang yang bersifat normative, tetapi diikuti dengan penetapan sanksi hukuman bagi peminum khamr. Dari hal tersebut dapat dicermati bahwa pengaruh hokum Islam dalam mengubah masyarakat sangat terasa. Paling tidak ada dua hal yang menjadi sebab mengapa kebiasaan mengkosumsi khamr itu dapat berhenti, pelarangan hukuman itu dapat maksimal (hokum haram), dan penetapan sanksi hokum bagi peminum khamr dapat diberlakukan (meskipun terdapat variasi jumlah hukuman), yaitu:

1. Kesadaran akan dampak negatif khamr yang sudah dirasakan oleh masyarakat yang diperkuat dengan petunjuk Allah dalam al-Qurán. Dalam hal ini, ada semacam persinggungan atau pertemuan antara ayat al-Qurán yang memberikan petunjuk tentang pelarangan khamr dengan apa yang mereka rasakan sebagai dampak negative dari kosumsi khamr. Persinggungan ini membuat mereka meyakini betul bahwa khamr lebih banyak madlarat dan lebih besar dosanya daripada manfaat atau keuntungan yang diperoleh.

2. Pendekatan larangan yang digunakan dalam al-Qurán tidak menyinggung (tidak melukai) secara langsung kebiasaan buruk yang terus berlangsung, tetapi dengan tahapan-tahapan yang membutuhkan waktu tidak sebentar. Ditambah dengan "pembiaran" agar masyarakat secara langsung dapat merasakan dampak negative mengkosumsi khamr. Pendekatan yang sangat bijaksana ini akan membuat masyarakat memiliki kesadaran tanpa harus dipaksa atau ditekan oleh peraturan atau oleh Nabi saw sekalipun. Soal variasi jumlah hukuman di masa Nabi saw dan di masa Umar, itu juga memberikan petunjuk betapa soal banyak dan sedikitnya, atau berat dan ringannya hukuman itu bukan menjadi tujuan pemberlakuan hokum bagi peminum khamr, akan tetapi kesadaran masyarakat bahwa khamr tidak bermanfaat untuk dikosumsi itulah yang menjadi tujuan utamanya. Sudah barang tentu, 
kesadaran akan pelarangan itu untuk melindungi mereka dari bahaya yang lebih besar maupun dosa besar.

\section{Penutup}

Dari beberapa uraian di atas dapat disimpulkan bahwa tujuan dilarangnya minuman keras tidak lain adalah untuk memelihara unsur pokok yang ada pada diri manusia, yaitu akal pikiran.

Tahapan dilarangnya minuman keras adalah agar tidak mempengaruhi kondisi sosial yang belum siap bila diberlakukan hukum secara spontan (sekaligus). Hal ini menunjukkan bahwa syari' sangat berhati-hati dalam memberikan ketentuan hukum. Penentuan hukuman yang bervariasi dengan batasan minimal 40 kali hukuman cambuk (di masa Nabi, Abu Bakar, 'Umar dan seterusnya) didasarkan kepada situasi dan kondisi yang terjadi di masyarakat.

Pengaruh hukum Islam sangat terasa dalam mengubah kebiasaan masyarakat yang gemar mengkosumsi khamr, karena dua hal; kesadaran social yang diperkuat dengan ayat dan pendekatan hokum yang digunakan dengan menggunakan prinsip pentahapan dalam pengharaman khamr.

\section{Daftar Pustaka}

'Awdah, 'Abd al-Qadir. al-Tashri' al-Jina'iy al-Islamiy. t.t.: Muassasah al-Risalah, t.t.

Dahlan, Abdul Aziz. et. al. Ensiklopedi Hukum Islam. Jakarta: Ikhtiar baru Van Hoeven, 1997.

Haramayn (al-), Mujamma' Khadim. al-Qur'an dan Terjemahnya. Madinah: t.p., t.t.

Jurjani (al-). Hikmat al-Tashri' wa Falsafatuh. Beirut: Dar al-Fikr, t.t. Khallaf, 'Abd al-Wahhab. 'Ilm Usul al-Figh. Kuwayt: Dar al-Qalam, 1978.

-. Khulasah Tarikh al-Tashri' al-Islamiy. terj. Aziz Masyhuri. Semarang: Ramadhani, t.t.. 
Mandhur, Ibn. Lisan al-Lisan Tahdhib Lisan al-'Arab. Beirut: Dar alFikr, 1993.

Maraghi (al-). Tafsir al-Maraghiy. Beirut: Dar al-Fikr, t.t.

Naysaburi (al-). Asbâb al-Nuzul. Beirut: Dar al-Fikr.

Sabuni (al-), Muhammad 'Ali. Rawâi' al-Bayân Tafsir Ayat al-Ahkam min al-Qur'an. Beirut: Dar al-Fikr, t.t.

Salih (al-), Subhi. Mabâhith fi 'Ulum al-Qur'ân. Beirut: Dar al-'Ilm li al-malayin, 1988.

San'ani (al-). Subul al-Salâm. Beirut: Dar al-Fikr, 1993.

Soekanto, Soerjono. Pokok-pokok Sosiologi Hukum. Jakarta: PT. Raja Grafindo, 1999.

Tabari (al-). Tafsîr al-Tabariy. Beirut: Dar al-Fikr, t.t.

Wahidi (al-). Asbâb al-Nuzûl. Beirut: Dar al-Fikr, 1987.

Zahrah, Muhammad Abu. Usul al-Figh. Beirut: Dar al-Fikr al'Arabiy, t.t. 